\title{
El travestismo de Penteo EN LOS RITUALES DIONISÍACOS Pentheus' travestism in Dionysian Rituals
}

Domingo Plácido SuÁrez

Universidad Complutense de Madrid

PLACIDO@GHIS.UCM.ES

\section{RESUMEN}

Bacantes de Eurípides resume en cierto modo la historia de la tragedia. Los rituales más primitivos se incorporan en la figura de Penteo y el travestismo. En Tiresias y Cadmo se impone la visión civilizada con que el ritual se incorpora en la ciudad de Atenas.

Ello se puede explicar al insertar la obra en las prácticas religiosas propias de los festivales dionisíacos y el proceso experimentado por ellos en la historia cultural y política de Atenas, que los obliga a interesarse por las vicisitudes propias de las preocupaciones cívicas de la democracia.

\section{Abstract}

Euripides's Bachhae contains to some extent the history of tragedy. The rituals most primitive are incorporated in the person of Pentheus and travestism. In Tiresias and Cadmus is imposed the civilized vision with the ritual that is incorporated in the city of Athens. This can be explained by inserting the work in the religious practices characteristic of the Dionysian festivals and the process experienced by them in the cultural and political history of Athens, which forces them to deal with the vicissitudes of the civic concerns of democracy.

\footnotetext{
* Agradezco sinceramente a los evaluadores anónimos sus indicaciones que me han permitido subsanar muchos aspectos de mi redacción así como recibir informaciones sobre detalles de gran utilidad para completar aspectos del tema tratado.
} 
PALABRAS CLAVE

Atenas, Bacantes, Eurípides, Penteo, ritual dionisiaco, travestismo

\section{KEYWORDS}

Athens, Bachhae, Dionysian ritual, Euripides, Pentheus, travestism

Fecha de recepción: 08/02/2019

Fecha de aceptación: 26/06/2019

ARYS, 17, 2019 [85-103] ISSN 1575-166X 
La TRAgedia de LAS BACANTES DE EuRíPIDES parece ser la plasmación teatral de rituales derivados de la práctica común del travestismo iniciático. Éste aparece en una serie de rituales, como las Oscoforias, en el mes de Pianepsión, en octubre, en las que se celebra una procesión de efebos disfrazados de mujeres. Se sitúa en la historia de Teseo al llegar a Atenas, según cuenta Plutarco, Teseo, 22, sobre la base de Demón, FGH 327 F6, dentro de la narración que ocupa 23, 2-5, sobre las Oscoforias: dice que entre las jóvenes colocó a dos muchachos disfrazados. La atención a las fiestas se confió al génos aristocrático de los Fitálidas.

Existen dudas sobre el itinerario preciso, en una fiesta atribuida a la época de la guerra con Eleusis. En la procesión de las Oscoforias, los jóvenes llevan ramas de viña, del santuario de Dioniso en Limnas al santuario de Atenea Esciras en Falero, con la presencia de mujeres deipnophóroi, portadoras de la comida, que representaban a las madres de los siete jóvenes de cada sexo rescatados por Teseo.

Se llevaban ramas en honor de Dioniso y Ariadna, la pareja formada después del abandono de ésta por parte de Teseo en Naxos. En las Oscoforias la procesión iba desde el santuario de Dioniso, seguramente en Limnas, donde se celebraban fiestas en honor del dios, a donde se lleva el vino nuevo y se sitúa el santuario de Dioniso más antiguo, según Tucídides (II 15, 3-6), o al de Atenea Esciras en Falero, con ramas de viña en los inicios de la vendimia. Se produce así la síntesis de Atenea y Dioniso a través de Teseo, el héroe ático. Sería además el origen de las relaciones de los atenienses con el mar (Plutarco, Vida de Teseo, 17, 6). El génos se conoce como los Salaminios, el que también administraba el culto de Atenea Escírade, en Falero y en Salamina (Heródoto, VIII 94). Áyax y Eurísaces se incluyen asimismo en el génos de los Salaminios que en la isla rendía culto a Esciras, que se sincretiza como Atenea Esciras.

En las Antesterias, en el mes de Antesterión, en febrero, que Hesiquio identifica como la Dionisias y que los atenienses celebraban el mismo mes, participaban dos jóvenes selectos travestidos, que iban con ropas femeninas. Como era normal entre los miembros de las familias aristocráticas, Alcibíades, seguramente del génos de los Salaminios, había ganado prestigio por intervenir en los juegos panhelénicos, donde 
llegó a invitar a un banquete a toda la "panegiria". El $\gamma \varepsilon ́ v o \varsigma$ de los Salaminios sacrificaba a Apolo Patroo, padre de Jon, origen de los jonios.

Las mujeres se relacionan con la comida, como deipnophóroi, y acompañan a los jóvenes al Falero, donde se celebran carreras de efebos y banquetes en que se narraban leyendas, seguramente la de Teseo en Creta, que decía que las madres llevaban la comida, con participación de las Tesmoforias. Se prescribe la abstención sexual previa. Nueve meses más tarde, se celebran las Esciras de verano, las Esciroforias.

El génos de los Eteobútadas se localiza en el dêmos Bouteía, donde se asentaban los Bútadas, que se sitúan justamente al oeste de Atenas. ${ }^{1}$ En el año 508, el génos está a su vez dividido en dos ramas, los Licómidas y los Salaminios, situados en diferentes dêmoi. ${ }^{2}$ En Atenas, los salaminios de Salamina, en cambio, pertenecían a una sola phratría, ${ }^{3}$ lo que indica que éstas no se han visto afectadas por la organización democrática, conforme a la afirmación aristotélica inicial. ${ }^{4} \mathrm{La}$ phratría conserva la composición antigua en relación con el génos, katà tà pátria. El papel político de Solón, en cuya carrera fue tan importante la reivindicación de la isla para Atenas, podía estar relacionado también con su vinculación con los Salaminios. Posiblemente sus miembros se situaron en la aristocracia a partir de relaciones clientelares con Eteobútadas o Filaidas, ${ }^{5}$ pues se mantienen en los círculos de unos o de otros.

Los Salaminios de Salamina aparecen como Erecteidas en Sófocles, Áyax, 201202, es decir, como miembros de la estirpe más ilustre de la historia mítica ateniense. Los cultos heroicos fueron revitalizados por la tragedia, con un destacado papel de las fiestas dionisíacas. Así se entiende la incapacidad de Temístocles para capitalizar en su favor la victoria naval que había promovido a través de su interpretación del oráculo délfico relativo a los muros de madera.

El culto de Aglauro, Pándroso y Herse o Gea Curótrofo pertenece también al génos de los Salaminios. ${ }^{6}$ Se trata de un culto vinculado al de la diosa patrona en la Acrópolis, en su identificación con las tradiciones más arcaicas relacionadas con Erecteo y Cécrope. ${ }^{7}$ También son miembros del génos las sacerdotisas de Atenea Escírade, así como los encargados del culto de Eurísaces, del héroe de Halas y el Heracles de Pórthmos, en Sunio. Todos los dêmoi de los Salaminios de las Siete tri-

1. Davies, 1971, p. 348.

2. Davies, 1971, p. 349.

3. De Schutter, 1987, p. 111.

4. Plácido, 2004.

5. Valdés, 2002, p. 177.

6. Garland, 1984, p. 86.

7. Plácido, 1995, pp. 207-215. 
bus están cerca de la ciudad de Atenas, ${ }^{8}$ por lo que el génos sobrevive a las reformas y no se adapta como tal a la estructuración de Clístenes. En Halas, el sacerdote de Apolo Zoster hacía sacrificios katà tà patria. ${ }^{9}$ Los sacerdocios de las tribus Erecteida, Cecrópida e Hipotóntida seguían en manos de los miembros de los grupos gentilicios. ${ }^{10}$ El culto de Heracles en Halimunte se atiende entre familias nobles, según Pseudo-Demóstenes, LVII Contra Eubúlides, 46, los que tienen derecho al sacerdocio, por la pertenencia al génos.

El héroe Esciro recibía en Falero un sacrificio anual por parte de los Salaminios. También ofrecían un sacrificio a Teseo en las Oscoforias, en la procesión que iba de Atenas al Falero. Las Oscoforias celebraban la partida de Teseo para Creta (Pausanias, I 1, 2; Plutarco, Vida de Teseo, 17). Llevaban ramas de viña, ôschon, y se hacían carreras de efebos en los festivales llamados Escira, en el mes de Esciraforión, último del año ritual ático. Los Salaminios se habrían trasladado a Atenas entre el siglo VII y el VI tras la guerra con Mégara por el control de la isla; se asientan cerca de Sunio y el Falero. El génos ha llegado a monopolizar la fiesta de las Oscoforias, como un arbitraje entre las dos ramas de Sunio y Falero, Oscóforos y Dipnóforos. Dos jóvenes selectos se presentan travestidos acompañados de mujeres con la comida: deipnophóroi. Acompañan a los jóvenes al Falero, donde se celebran carreras de efebos y banquetes en que se narraban leyendas, seguramente la de Teseo en Creta, que decía que las madres llevaban la comida. Se arrojaban objetos simbólicos de la fertilidad en las cuevas. En el mismo mes se celebran las Apaturias, y las Calqueas el día 30. Las Apaturias son la fiesta de las fratrías. El

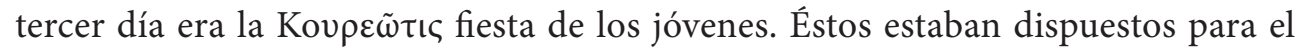
matrimonio, pero las novias no asistirían. Nueve meses después de las Gamelias se celebran las Calqueas con el protagonismo de Hefesto y Atenea, nueve meses antes de las Panateneas de 3 días, cuando se presente el peplo a Atenea. ${ }^{11}$

Atenea Prómaco y Atenea Lemnia también están presentes en la Acrópolis (Pausanias, I 27, 3). Sin embargo, de los rituales de la Acrópolis, Pausanias destaca los de las Arreforias, de las dos doncellas, seleccionadas por el arconte rey, que pasan el año retiradas en el lugar próximo al templo de Atenea Políade y, cuando llega la fiesta, a principios del verano, transportan la caja secreta y la bajan al lugar dedicado a "Afrodita en los Jardines", donde se encuentran Afrodita y Eros. Existe pues una

\footnotetext{
8. Osborne, 1994, p. 155.

9. Garland, 1984, p. 109.

10. Kearns, 1985, p. 193.

11. Valdés, 2015, pp. 19-40.
} 
vinculación entre Atenea y Afrodita a través de la fiesta de las Arreforias. En la ladera se halla la Cueva de Aglauro, por donde pasan las Arreforias. El festival colectivo se celebra en honor de Aglauro, Pándroso y Herse, las hijas de Cécrope, y se considera como mistérico e iniciático, con la práctica de la deipnophoría, en que los jóvenes llevan comida a las jóvenes mencionadas. El sacerdocio está en poder del génos de los Salaminios, en que el culto de Aglauro y Pándroso está relacionado con Gea. El Pandroseo se halla vinculado por los muros al Erecteo. En cambio, el culto de su padre Cécrope lo asumía un miembro del génos de los Aminándridas.

Igualmente, la historia de Aquiles en Esciro tal como se narra en Pausanias, I 19, 1, representa un rito de travestismo. Hay otras historias de travestismo. Los mesenios, en efecto, acusan a los espartanos de venir atraídos por la chóra de Mesenia (Estrabón, VIII 4, 3). Habían introducido jóvenes vestidos de muchachas, en lo que parecerían rituales iniciáticos de travestismo, convertidos en conflictivos en el espacio fronterizo.

Filócoro, F15, en Ateneo, XI 495E-496E, se refiere a juegos en Esciro, con carrera de efebos desde el santuario de Dioniso, con el "osco", ramo de vid, hasta el templo de Atenea Skirás, probablemente el del Falero Los jóvenes iban con vestidos femeninos (Plutarco, Teseo, 23, 2-3), como los jóvenes que habían acompañado a Teseo a Creta, ${ }^{12}$ en lo que se considera el origen de las Oscoforias.

En las Pianepsias propiamente dichas, las que dan nombre al mes de Pianepsión, el séptimo día se celebraba el regreso de Teseo con la comida de una mezcla de legumbres cocidas, en la que participaban todos. La fiesta estaría relacionada con la época de la siembra de los vegetales comestibles. La fiesta se relaciona igualmente con la Eiresione, también vinculada con Apolo. La procesión se celebraba con ramas adornadas con frutas. Era la época de la vendimia. Se entonaban cantos y llantos, por el regreso de Teseo y la muerte del padre. Aquí también, tras el sacrificio y la ofrenda a Apolo, con los restos se celebraba un banquete. Llevaban ramas de viña, ôschon, y se hacían carreras de efebos en los festivales llamados Escira, en el mes de Esciraforión, último del año ritual ático. Dos jóvenes iban con ropas femeninas, según Plutarco, Vida de Teseo, 23.

Bacantes de Eurípides responde a una tendencia frecuente en la época a remontarse a los orígenes frente a la gravedad de los problemas de su tiempo; ${ }^{13}$ se presenta como tragedia dionisíaca en las fiestas del travestismo. ${ }^{14}$ En ella se detectan rasgos del culto. ${ }^{15}$ De hecho es la única tragedia propiamente dionisíaca con-

12. Costa, 2007.

13. Green, 1994, p. 47.

14. Grégoire, 1961, pp. 207, 219.

15. Lacroix, 1976, p. 8. 
servada. ${ }^{16}$ Son las fiestas de expulsión de la vegetación de la estación que ha pasado, con una víctima travestida. Hay varias tragedias dionisíacas en que domina el tema de la locura de las mujeres, como la de las mujeres de Tebas en Bacantes por Dio-

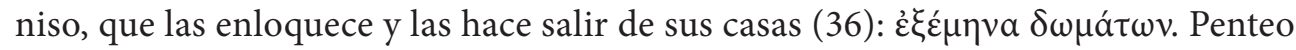
amenazaba con perseguirlas en la primera parte de la trilogía en Esquilo. ${ }^{17} \mathrm{El}$ árbol pertenece a la leyenda etiológica del rito. Es la obra de lenguaje más arcaico determinado por el tema, ${ }^{18}$ propio de la religión dionisíaca, como se ve en el uso de

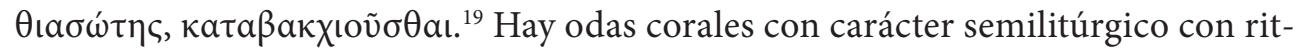
mos asociados a los cultos como en stásimon III (862-911). ${ }^{20}$ Emplea versos jonios típicos del Dionisismo, como en la párodos de 64-169 uu-- <breve breve larga larga $>$ (desde el v. 84), que suele asociarse con formas orientalizantes, ${ }^{21}$ aunque ésta no sea más que una de las dicotomías que invaden las formas ideológicas de los griegos. ${ }^{22}$ Se produce una tensión entre la formalidad clásica y las experiencias religiosas, el orden y la emoción, ${ }^{23}$ con un elogio de la inteligencia instintiva del pueblo. La obra plantea el problema básico del Dionisismo: si el humano no reconoce la experiencia dionisíaca y la rechaza, el dios se transforma en un poder destructivo: la justicia natural no tiene réplica. ${ }^{24}$ Sería como el rechazo de la naturaleza.

En esta tragedia Penteo se disfraza para ver los ritos de las mujeres. Ha heredado

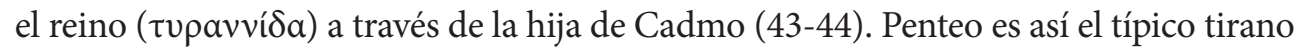
de la tragedia, ${ }^{25}$ lo que marca la representación del poder, incluso en personajes que la tradición, desde Roma, traduce como rey; tal es el caso de Edipo, aunque hay que tener en cuenta que Rex es el término latino adecuado para el tirano desde figuras como Tarquinius Superbus. La ambigüedad sólo se romperá con Percy B. Shelley, que tradujo Oidipus Tyrannus. Las mujeres celebran un thíasos femenino. Desde el verso 72, el

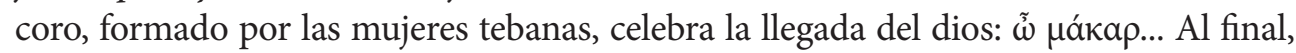
la muerte de Penteo aparece como una bendición resultado del agón. ${ }^{26}$ Representan rituales como los descritos por Plutarco, Cuestiones romanas, $112=$ Morales, 291A, para

\footnotetext{
16. Lacroix, 1976, p. 9.

17. Grégoire, 1961, p. 222.

18. Dodds, 1944, p. xxxii.

19. Dodds, 1944, p. xxxvii.

20. Dodds, 1944, p. xxxviii

21. Hall, 1989, p. 82.

22. Hall, 1989, p. 152.

23. Dodds, 1944, p. xxxviii.

24. Dodds, 1944, p. xlv.

25. Dodds, 1944, p. xliii.

26. Thomson, 1946, p. 141.
} 
la locura de las mujeres. Están poseídos como las bacantes, dice Platón, Ion, 533E. Se

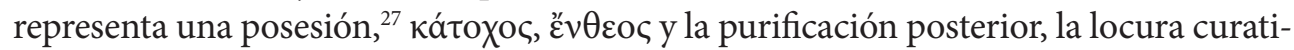
va que caracterizaba a los Coribantes. ${ }^{28} \mathrm{El}$ intruso entra travestido, ${ }^{29}$ lo que es propio de festivales dionisíacos, con adornos y estolas como los clérigos, tal vez como herencia de sacerdocios femeninos, con los hombres como meros espectadores. Dioniso se confiesa

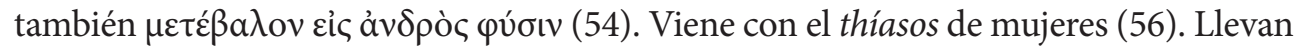
los tímpanos de la madre Rea (59). Hay también una contraposición entre el palacio

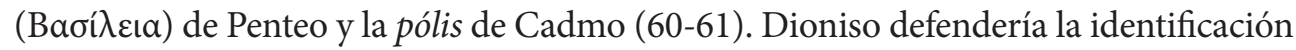
de la pólis con la introducción de cultos mistéricos frente al palacio de Penteo, que será descubierto. El inicio (68-77) se relaciona con los misterios órficos. ${ }^{30}$

El que lleve tiasos es Bromio (115), nombre de Dioniso, pues en el ritual hay una transformación. Lo acompaña la masa femenina alejada de los telares,

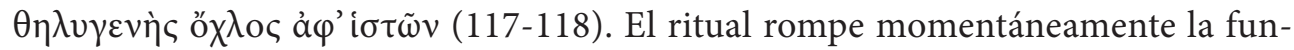
ción convencional femenina.

Pero era frecuente el disfraz, según se deduce de Luciano, Que no debe creerse fácilmente una calumnia (De cal.) 16. Dice que en la corte de Ptolomeo (Auletes, padre de Cleopatra) llamado Dioniso, uno acusaba al platónico Demetrio de beber sólo agua y no llevar ropa femenina en la fiesta de Dioniso.

Como ya se señala en la "Hipótesis", Penteo se disfraza para unirse a las mujeres y espiar, persuadido por Dioniso, para poner a prueba su escepticismo. Al final de la misma, en un texto corrupto, se pone de relieve la diferencia de actuar, épyoıs, ivva

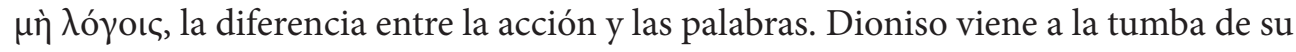
madre Sémele y recuerda la hýbris de Hera (9). Sémele es la diosa ctónica de Tebas, como en Diodoro, III 62, y Apolodoro III 5, 3. Con ả $\mu \pi \varepsilon ́ \lambda$ ov en el v. 11 se marca ya el carácter dionisíaco ${ }^{31}$ de la escena. Ha venido por tierra a través de ciudades mezcladas de griegos y bárbaros (18). Tebas aparece como la primera ciudad después de Asia (20-22), donde se manifiesta el culto orgiástico, ả $v \omega \lambda o ́ \lambda v \xi \alpha$ (24). Se plantea el dilema entre Sémele como $v v \mu \varphi \varepsilon v \theta \varepsilon i ̃ \sigma \alpha \nu$ (28), eufemismo por "seducida", 32 por un mortal, o la paternidad de Zeus. Las mujeres enloquecidas habitan el monte (33). Dioniso las obliga a llevar el atavío, skeué, de las orgías (35), donde se impone la exclusión de los varones (35-36).

\footnotetext{
27. Thomson, 1946 , pp. 374, 377-378.

28. Thomson, 1949, p. 459.

29. Thomson, 1949, p. 486.

30. Thomson, 1955, p. 275.

31. Dodds, 1944, ad loc.

32. Dodds, 1944, ad loc.
} 


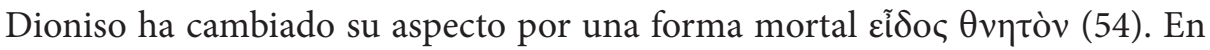
el coro de 64-169, se trata de la recuperación de las prácticas primitivas, en una procesión, ó $\delta \tilde{\omega}$ (68-71), y un himno ritual a Dioniso (71-72), con metro tradicional y

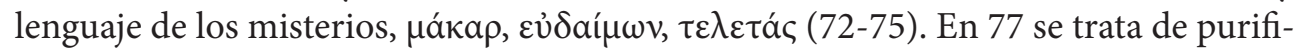

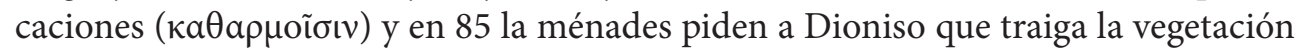

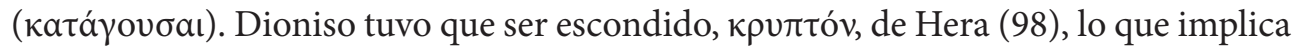
secreto en su nacimiento. En los ritos están presentes también los árboles (109-110).

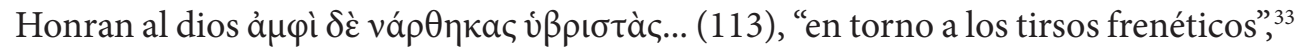

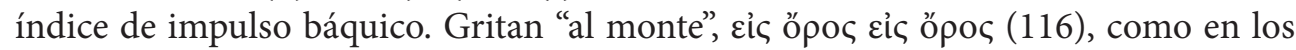

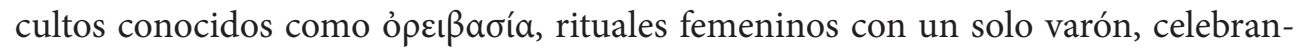
te identificado como Baco. Se dirigen al monte, donde está la multitud de mujeres aguijoneadas por Dioniso (118-119), que las libera del telar para pasar a convertirse en cazadores, en una inversión de los papeles de género. ${ }^{34}$ En 133 menciona las $\tau \rho ı \eta \tau \rho i ́ \delta \omega v$, fiesta bienal orgiástica por la epifanía de Dioniso, según Diodoro, IV 3. ${ }^{35}$ En los montes, se consume carne cruda, con sangre del macho cabrío (136-141). El dios se encarna temporalmente en el celebrante (144-150).

Desde 170 a 369, según Dodds, destaca el protagonismo de Tiresias, con una visión ilustrada del dionisismo, al que tratan de helenizar y racionalizar las nuevas corrientes. Desde 179 Cadmo busca la sophía en el dios. Junto con Tiresias tratan de racionalizar su propia conversión al culto dionisíaco como contraste a las danzas de las ménades de la párodos. ${ }^{36}$ Cadmo viene con el atavío, skeué, del dios (181). El culto busca aumentar, $a u ́ \xi \varepsilon \sigma \theta a$, el poder de la divinidad más que enunciar la petición. ${ }^{37}$ "Olvidamos que somos viejos" (188-189). Tiresias considera que sólo ellos, él y Cadmo, son sensatos y danzan en honor de Baco (195-196). Sólo son sensatos

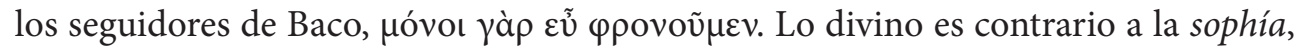

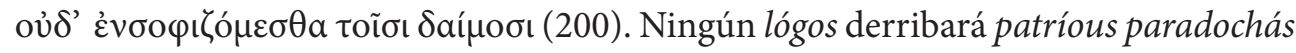

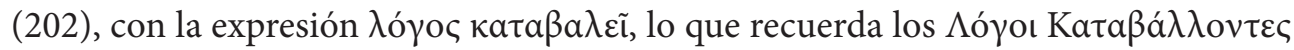
de Protágoras ${ }^{38}$ (DK80B1) y, por tanto, definen la actitud de Tiresias, entre el racionalismo y la irracionalidad, que en gran medida caracteriza la obra de Eurípides. ${ }^{39} \mathrm{El}$

33. Trad. Rodríguez Adrados, 1990, Madrid.

34. Rehm, 1992, p. 13.

35. Dodds, 1944, ad loc.

36. Rehm, 1992, p. 57.

37. Dodds, 1944, ad loc.

38. Lacroix, 1976, p. 15.

39. Diller, 1983, p. 358. 
dios no distingue edades (206). Quiere honras comunes (208-209). Aparece entonces

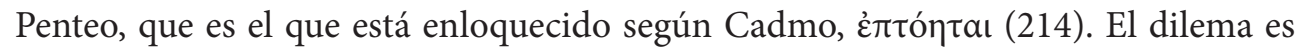
quién está loco, ¿las bacantes o sus críticos desde la razón?

Penteo se queja de que las mujeres han abandonado las casas (217) para honrar

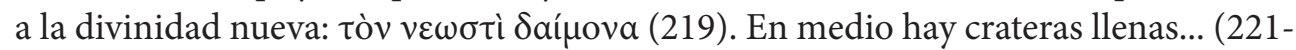
222). En lugares desiertos buscan la unión con hombres (223). Honran a Afrodita más que a Baco (225), pero el coro también querrá dirigirse a Chipre como isla de Afrodita (402-403). Penteo califica a Dioniso de góes, "brujo", de Lidia (234). Destaca su aspecto afeminado, como ocurría en Esquilo, Edonos, fr. 72. Penteo amenaza con la represión. Considera $\theta \alpha \tilde{v} \mu \alpha$, "un prodigio", ver a Tiresias y a Cadmo disfrazados

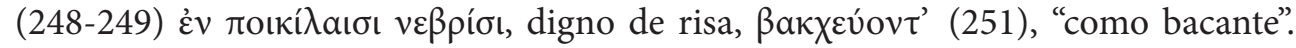
Se avergüenza de verlos bailar (251) y se escandaliza de que las mujeres beban vino

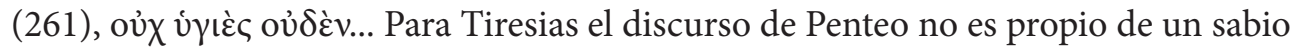
(266-269), voũv oủк $\varepsilon_{\chi} \chi \omega v$ (271). En cambio, Tiresias se refiere a un falso Dioniso

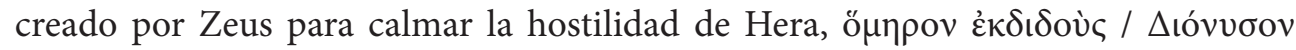

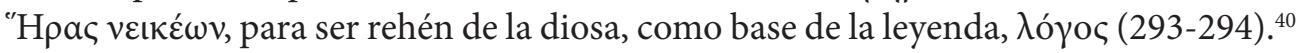

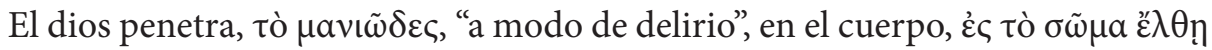

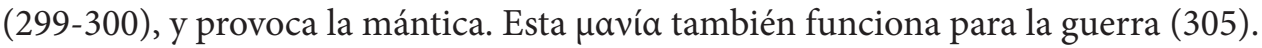

Habla Tiresias (entre 314 y 318 ) sobre el hecho de que Dioniso no fuerza a las

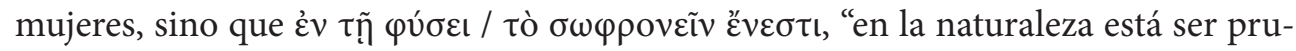
dente" y, si es $\sigma \omega ́ \varphi \rho \omega v$, ni en las fiestas báquicas se corromperá. No hay moralidad propia de Dioniso. ${ }^{41}$ Eurípides refleja el conflicto, no toma partido, ${ }^{42}$ pero busca representar la liberación.

El coro considera que Tiresias ha sabido conciliar a Apolo y Dioniso (328-329). El dionisismo se integra a través de Apolo, de la sophrosýne. Igual que la tragedia, cuando se convierte en actividad cívica. Sería un proceso como el de Delfos con el dionisismo. ${ }^{43}$ Representa la integración conflictiva propia de la ciudad y de la tragedia misma como género. Cadmo ataca el falso racionalismo de Penteo: $\varphi \rho o v \tilde{\omega} v$ oủ $\delta \dot{v} v$

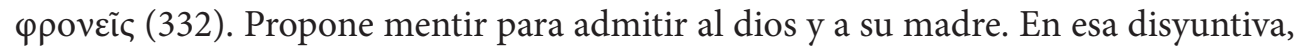
Penteo ni es un héroe ni un ilustrado. ${ }^{44}$

40. Ver traducción y nota de Grégoire, 1961.

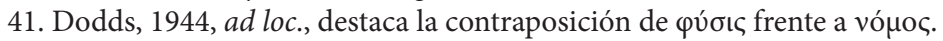

42. Dodds, 1944, pp. xlvi-xlvii.

43. Dodds,_1944, ad loc.

44. Diller, 1983, p. 364.

ARYS, 17, 2019 [85-103] ISSN 1575-166X 
Dioniso es atacado por Penteo como extranjero que además adopta forma femenina, thelýmorphon (353). ${ }^{45}$ Según éste, trae la locura a las mujeres y ultraja los lechos (354). Luego, en 359, Tiresias marca el contraste entre dos manifestaciones de

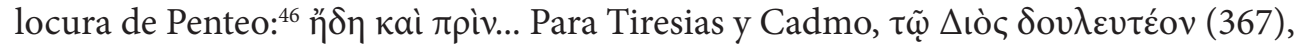

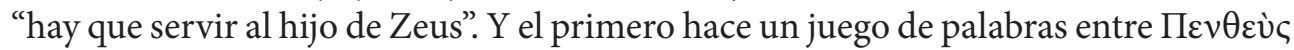
y $\pi \varepsilon ́ v \theta o \varsigma(367)$, que en las traducciones suele requerir explicación.

El coro invoca a la Piedad, 'Ooía, frente a la hýbris de Penteo, que se opone

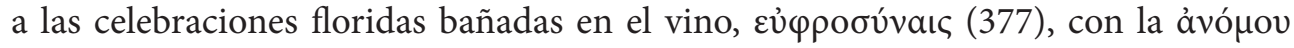

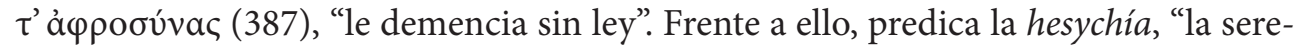

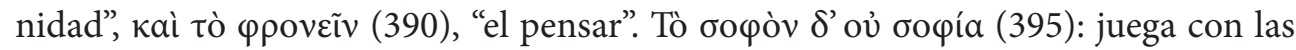
paradojas, que permiten afirmaciones como éstas para contraponer una sabiduría a otra, el saber místico o revelado y el saber racional, dentro de los problemas lingüísticos que caracterizaron los debates intelectuales del siglo $\mathrm{V}$ ateniense: ${ }^{47} \varphi \rho$ poveiv, pero no fuera de los límites humanos (396). Por perseguir grandes cosas se escapa el

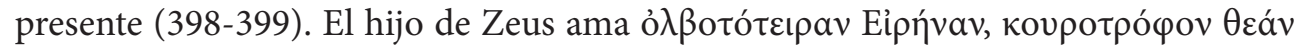
(419-420), "la paz, diosa nodriza de jóvenes, portadora de la paz", ${ }^{48}$ como la estatua

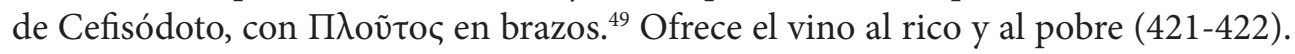
Se presenta explícitamente a Baco como dios interclasista. Odia al que no quiere vivir

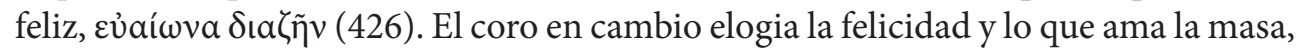

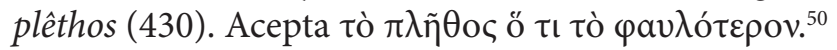

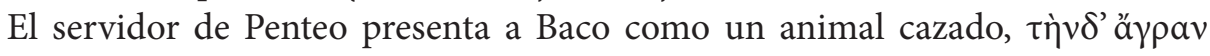

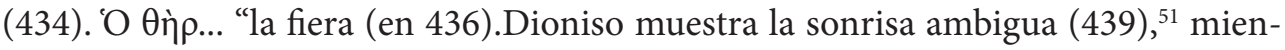
tras Penteo acusa a Dioniso de raptar, бvvń ne a llenar de maravillas ( $\theta a v \mu a ́ t \omega v)$ la ciudad de Tebas (449).

Penteo reprocha a Dioniso su aspecto femenino (453-459), no marcado por la lucha, sino pleno de amor, $\pi$ ó$\theta$ ov $\pi \lambda \varepsilon \dot{\varepsilon} \omega \varsigma$ (456), de piel blanca (457), como los orientales y las mujeres. No expuesto al sol, sino a la sombra (458), cazando a Afrodita con la belleza (459). Penteo cuestiona que Zeus engendre "nuevos dioses" (467). Inter-

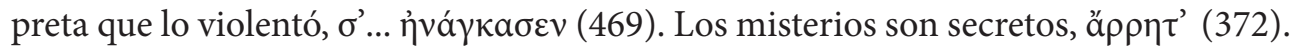

45. En su comentario, Dodds cita Esquilo fr. 61, pero Eurípides sigue también la tradición ya presente en Esquilo fr. 448. Éste dedicó al tema una trilogía entera (Lacroix, 1976, p. 12).

46. Dodds, 1944, ad loc.

47. Wise, 1998, p. 54.

48. Plácido, 1996, pp. 55-66.

49. Dodds, 1944, ad loc.

50. Ver Himnos homéricos IV (Himno a Dioniso I), 14.

51. Dodds, 1944, ad loc. Como hará de nuevo en 1020-23.

ARYS, 17, 2019 [85-103] ISSN 1575-166x 
Penteo le pregunta si viene con su Saínova (481). Los bárbaros los celebran (482). Todos los bárbaros "procesionan" esta orgía, dice Dioniso (482). Penteo lo atribuye a la inferioridad intelectual con respecto a los griegos (483). Dioniso aclara que sólo difieren los nómoi (484). Penteo opina que es porque son peores de mente que los

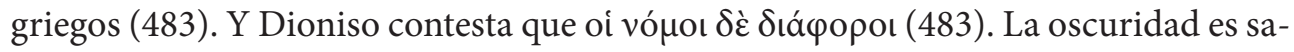
grada (486). Penteo amenaza con castigar por los sofismas (489). Dioniso le reprocha en cambio su ignorancia e impiedad (490). También Penteo lo acusa de no inexperto

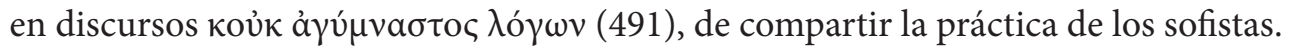

Penteo amenaza con cortarle la "afeminada cabellera", habròn bóstrychon (493).

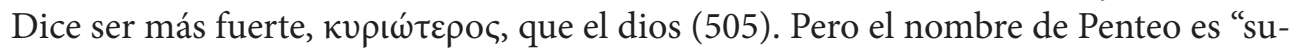
fridor" (508). Amenaza con vender como esclavas a las bacantes (514) y llevarlas al telar de donde las ha liberado Dioniso (en 118). ${ }^{2}$

La invocación del coro (520-603) invita a Ditirambo a entrar "en mi varonil matriz" (526-527), ${ }^{53}$ donde usa $v \eta \delta v ́ \varsigma$ que se puede referir al estómago pero más específicamente al vientre femenino, y así lo consideran LS y Tovar. Penteo se presenta como un monstruo (539) $\chi$ Өóvıov, hijo de Equión, también ctónico (541), y como un gigante (544). Ahora se trata de castigar la hýbris del hombre asesino (555). Reclama al portador del tirso (557) para los tíasos (558), con referencia a Orfeo (562). Llegará

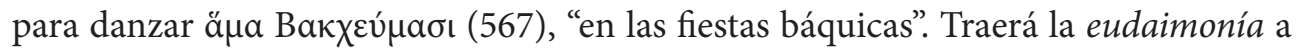
los mortales (572). Dioniso desde la prisión reclama a las bacantes (578). Pide quemar la casa de Penteo (595). Dioniso aparece ahora como ánax que destruye el palacio de Penteo (602). Este segundo stásimon contrasta con la violencia desatada a

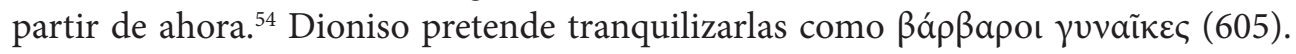

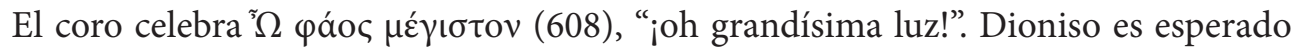
como $\varphi v ́ \lambda a \xi$ y liberador (612-613). Se ha liberado solo (614), proclama él mismo.

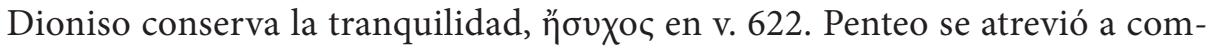

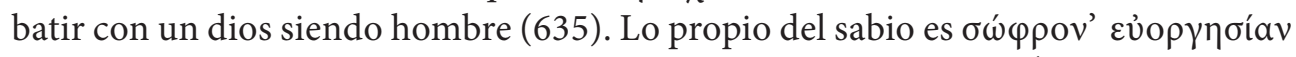
(641), "un temple moderado". Para Penteo, Baco es ó Ǵvoc (642). Éste le recomien-

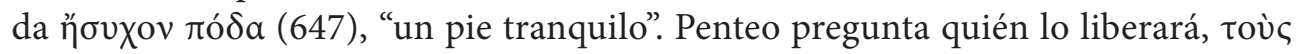

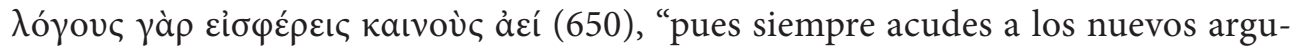

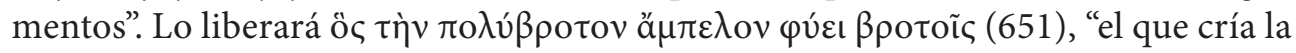

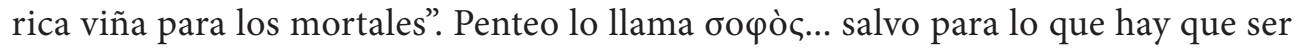

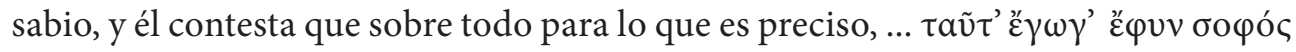

52. Ver Rodríguez Adrados, 1990, ad loc.

53. Traducción de Tovar, 1982.

54. Rehm, 1992, p. 103.

ARYS, 17, 2019 [85-103] ISSN 1575-166X 
(655-656), "es cuando soy sabio". El mensajero teme al poder $\beta a \sigma ı \lambda ı$ ı̀v de Penteo (671). Puede superar los muros de la ciudad. Penteo se pronuncia contra el que ha

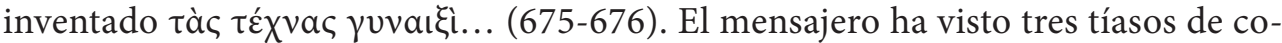
ros femeninos dirigidos por Autónie, Ágave e Ino (681-682). Todo en un ambiente pastoril, no enloquecido (686-688), alternativo al de Ágave (720). Las Ménades no

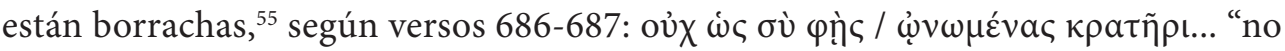
como tú dices"; de nuevo trataría de un ritual de invierno, no de primavera, cuando se abría el vino nuevo, en las Antesterias.

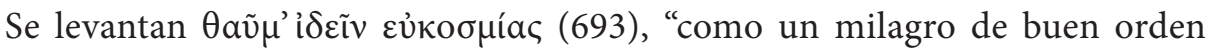
digno de verse", en contraste con la orgía. Las imágenes (695-713) responden a la iconografía de las bacantes: ${ }^{56}$ con la simbología de la abundancia. Los pastores co-

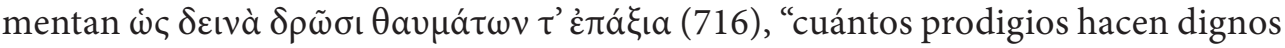

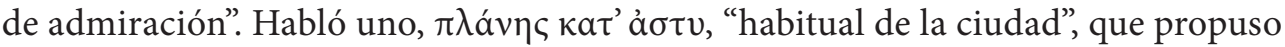
salir a cazar a Ágave (717-719). Ágave ordena atacarlos (728-733). Nos libramos del

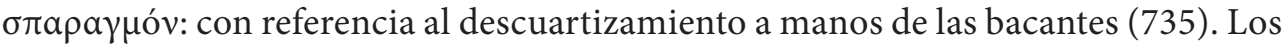

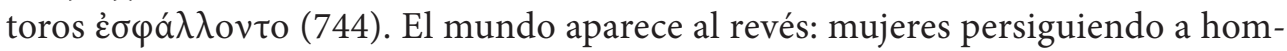
bres (764). El mensajero pide a Penteo que reciba al dios en la ciudad (770), pues dio la viña $\pi \alpha v \sigma i ́ \lambda ı \pi o v$, "que acaba con las penas", a los mortales (772). Sin vino no

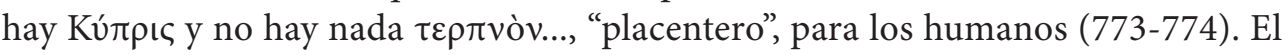
pueblo se inclina por la aceptación frente al tirano. ${ }^{57} \mathrm{El}$ coro declara que hablará libremente al tirano a pesar del temor: "Dioniso no es menor que ningún dios" (775-777). La reacción de Penteo es bélica (779-786), indignado por tener que enfrentarse a mujeres, $\ddot{\beta} \rho\llcorner\sigma \mu \alpha \beta \alpha \kappa \chi \tilde{\omega} v$; no soporta que venga de mujeres. Dioniso

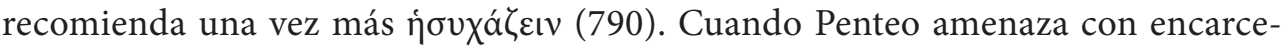

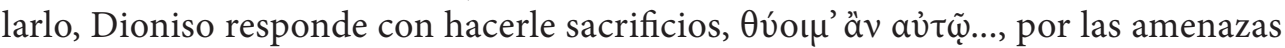
$\theta v \eta \tau o ̀ s ~ \omega ̈ v ~ \theta \varepsilon \tilde{~(794-795), ~ " a ~ u n ~ d i o s ~ s i e n d o ~ m o r t a l " . ~ P e n t e o ~ a m e n a z a ~ a ~ s u ~ v e z ~ c o n ~}$ hacer sacrificio de mujeres, $\varphi$ óvov $\gamma \varepsilon \theta \tilde{\eta} \lambda u v$ (796).

Los escudos retrocederán ante los tirsos de las bacantes, según Dioniso (798799). Penteo considera que ceder es servir a sus esclavos (804). Dioniso declara que lo que quiere es salvarlos (806). En el verso 810 se produce un cambio en la actitud de Dioniso ${ }^{58}$ cuando Penteo quiere ver a las bacantes en acción (811-820) en los montes y declara que quiere ver "penosamente", $\lambda \nu \pi \rho \tilde{\omega} \varsigma$ (814), y Dioniso se sorprende de que

55. Dodds, 1944, p. xiii.

56. Grégoire y Meunier, 1961, ad loc., citando a Phillipart, 1940.

57. Rodríguez Adrados, 1990, ad loc.

58. Grégoire, 1961, ad loc. 


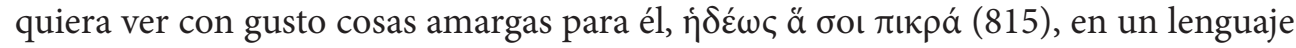
absolutamente paradójico, parte del comportamiento general del dios frente a Penteo, en una especie de estrategia de la confusión. Dioniso se propone cubrirse con $\beta v \sigma \sigma i ́ v o v \varsigma$ $\pi \varepsilon ́ \pi \lambda$ ovৎ (821), "con peplos de lino", tal como aparece en la cerámica. ${ }^{59} \mathrm{Y}$ viene la propuesta a Penteo de vestirse de mujer (822), cis yvvaĩkac, "para que no te

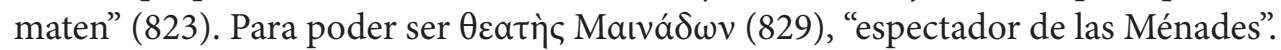

El travestismo de expresa en 831-833, donde Penteo se pone una peluca, кó $\mu \eta v$, vestidos largos y la $\mu$ í $\rho \alpha$; ya fuera de sí, tomará forma de mujer, үuvaıкó $\mu о \rho \varphi o v$,

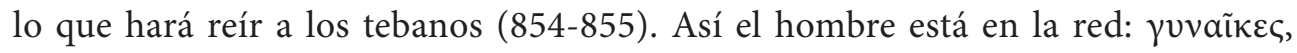

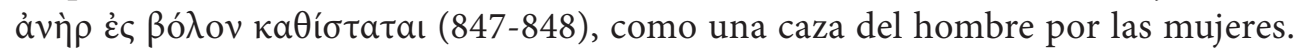
Estará fuera de sí. Entonces es cuando Dioniso entra en él. ${ }^{60}$ Pone a Penteo fuera

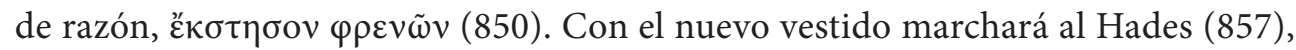

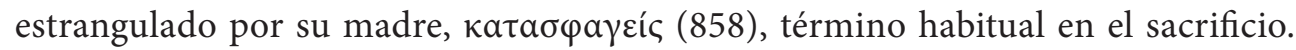

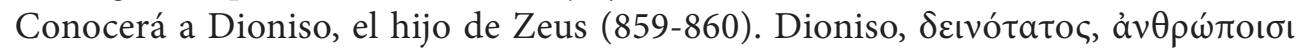

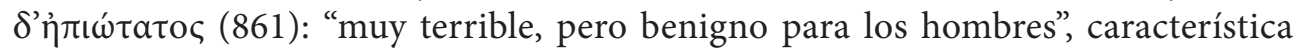
del dios así como de la tragedia y de los espectáculos dionisíacos. El coro canta la imposición de la piedad.

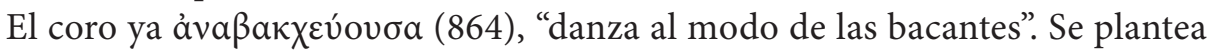

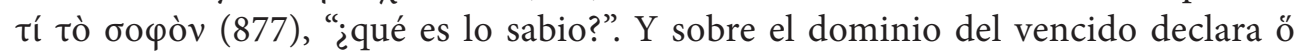

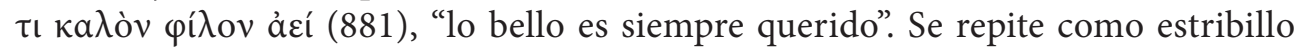
(897-901). En el epodo de versos 903-911, expone una especie de letanía con la

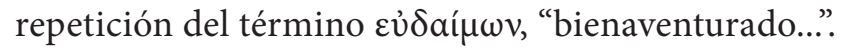

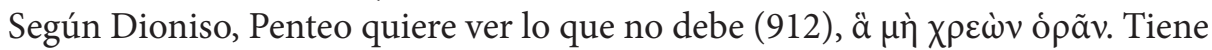
que mostrarse travestido para espiar (913-916), como una de las hijas de Cadmo, y lo llama a salir de casa. Penteo comienza a ver a Dioniso como un toro (920), en recono-

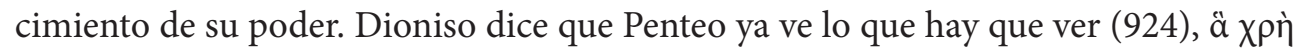

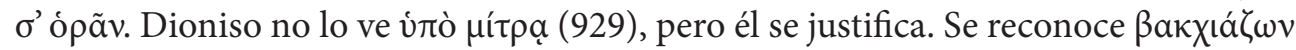

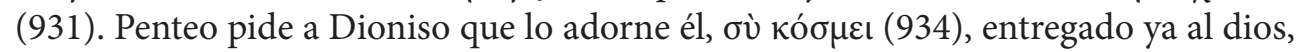
"en una grotesca parodia de la coquetería femenina". ${ }^{61} \mathrm{El} \mathrm{hecho} \mathrm{de} \mathrm{que} \mathrm{el} \mathrm{peplo} \mathrm{llega}$ hasta el pie (937) le confiere un aspecto fúnebre que lo identifica con un cadáver. ${ }^{62}$

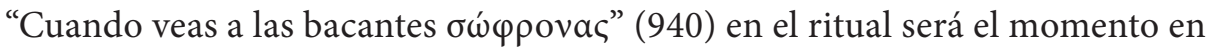
que cambie la visión de Penteo; es el momento en que se ha transformado su mente:

59. Rodríguez Adrados, 1990, ad loc.

60. Dodds, 1944, p. xxviii.

61. Zeitlin, 1990, p. 74.

62. Rehm, 1992, p. 67. 


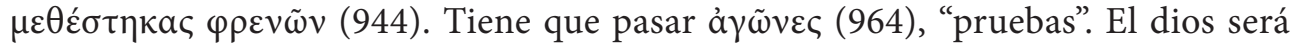
$\sigma \omega \tau \eta ́ p ı$ (965), "salvador". Dioniso le dice que va a terribles sufrimientos, $\pi a ́ \theta \eta$,

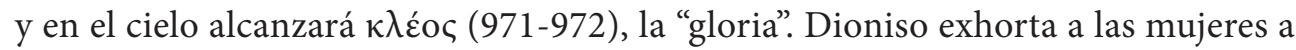

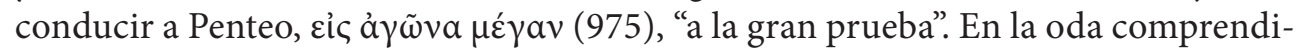
da entre los versos 977 y 1023, compuesta de estrofa, antistrofa y epodo, se propone la venganza por la actuación de Penteo, en forma de sacrificio. ${ }^{63}$ Las bacantes lo atacan por espiar con vestimenta femenina (980). Penteo es calificado como $\gamma \varepsilon \gamma \varepsilon v \tilde{\eta}$ (996 y 1016), "nacido de la tierra”. Con él cae la próspera casa de Cadmo (1024). Se muestra como gran dios a Bromio (1031). Dioniso se coloca por encima de Tebas (1038). Él pone a Penteo en un árbol y lo eleva y expone al castigo de la Ména-

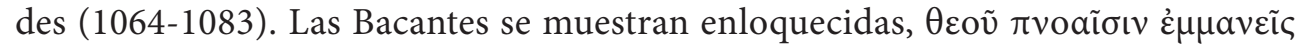

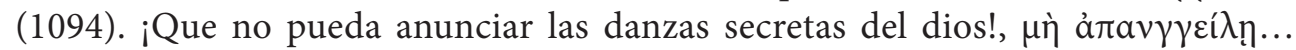
(1108). En su furor, arrancan el árbol (1110).

Se trata de una exposición propia del culto desde el verso $992,{ }^{64}$ como invocación,

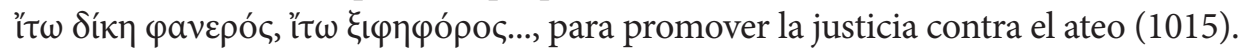

El mensajero anuncia la muerte de Penteo (1030) y el coro celebra la grandeza del dios (1031). Queda destrozado como el propio Dioniso con los Titanes. ${ }^{65}$ Dioniso, no Tebas, tiene el poder, krátos (1037-1038). Penteo se vuelve a Citerón como despótes

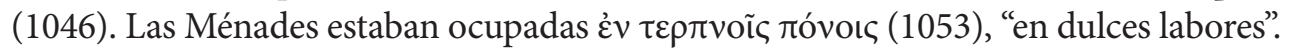

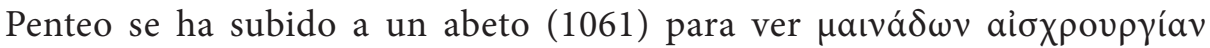
(1062), “acciones impúdicas de las ménades", los actos obscenos con que se restaura la fertilidad, por ejemplo en el Himno homérico a Deméter. El mensajero

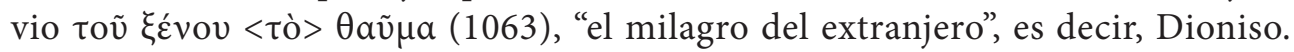
Dobla el abeto como un arco (1066). Ofrece la víctima a las ménades para el castigo (1081). Apareció una luz de fuego sagrado (1083). La ménades saltan $\theta \varepsilon$ ov $\pi$ voaĩoı $\varepsilon \mu \mu a v \varepsilon \tilde{c} \varsigma$ (1094), "enloquecidas por la inspiración del dios". Para

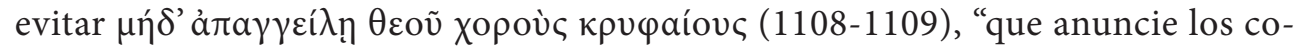

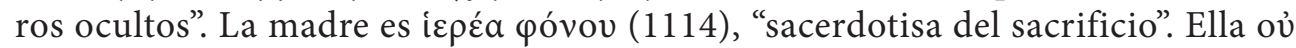

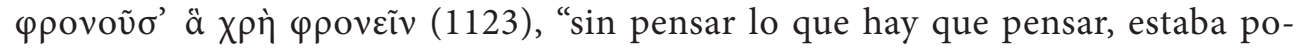
seída por Baco" (1124)... Como en muchas ocasiones, la escena más dramática aparece en boca de los mensajeros. ${ }^{66}$

63. Wiles, 1997, p. 97.

64. Dodds, 1944, p. xxxviii.

65. Thomson, 1946, p. 141

66. Rehm, 1992, p. 62. 
La homofagia, a partir del v. 1125, mezcla el gusto y la repugnancia, como indica Plutarco, Sobre la falta de oráculos, $14=$ Morales, 417C, que cita a Heródoto II 171, para referirse a sacrificios cruentos con $\omega \mu$ но $а \gamma i ́ a$ y otras prácticas, igual que Píndaro, fr. 208, 10-11 Christ $=61$ Bowra $=70$ Schroeder. ${ }^{67}$ Colabora la masa de las bacantes, óchlos (1130), en la destrucción del cuerpo, 1135: sparagmoîs. Se sucede el triunfo y la desgracia: 1147, el triunfo con lágrimas.

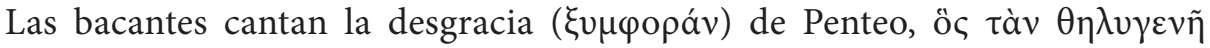

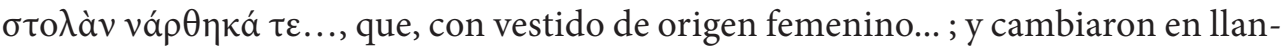

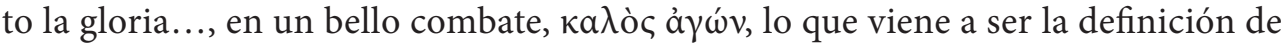
la tragedia...; se propone bañar la mano en sangre del hijo (1154-1164). Corre Ágave enloquecida y van a recibir el kômon del dios (1166-1167); invoca a las bacantes

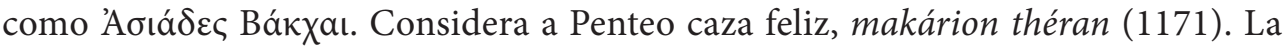
caza es eutychés (1183), "afortunada". Ágave invita a la participación en el banquete:

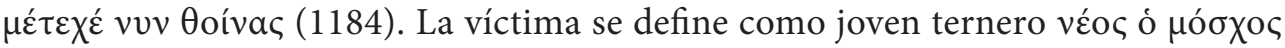

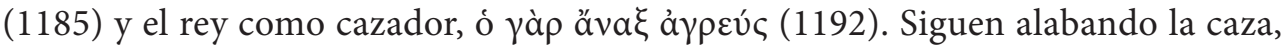
perissán "sublime" (1197). Han cazado con sus blancos brazos (1206). Alardea de la pieza cobrada e incluso llama a Penteo para enseñársela (1212).

Cadmo lo considera un asesinato (1245), un castigo del dios (1250), frente al entusiasmo de Ágave. Ésta atribuye las palabras de Cadmo a la torpeza de la vejez (1251). Cadmo advierte del dolor que sufrirán cuando comprendan, $\varphi \rho o v \eta ́ \sigma \alpha \sigma \alpha ı$ (1259). Ágave cree que ya está libre de la locura (1270). Ha olvidado lo anterior (1272). Reconoce a Penteo con espanto (1282) y se considera desgraciada, tálaina

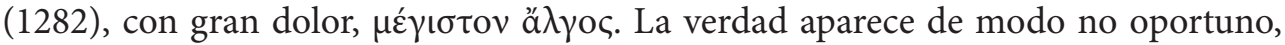
Ėv ov̉ kaıpụ (1287). Según Cadmo, Penteo había ido al Citerón a burlarse del dios (1293). Las mujeres estaban locas (1295) y toda la ciudad exebakcheúthe (1295), "fue poseída por Baco". El dios los castigó a él y a ellas (1303). Ágave muestra cómo ha

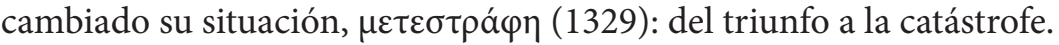

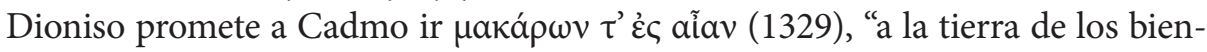
aventurados" con Harmonía. Cerca del final (1348-1349), entre Ágave y Dioniso proponen que los dioses eliminen la crueldad hacia los humanos con muestras de simpatías hacia las víctimas del dios, que los dioses no se asemejen a los mortales (habla Ágave o Cadmo, p. e. en Adrados). Dioniso ha castigado porque su nombre no era honrado en

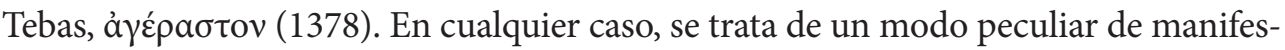
tarse la divinidad en el final de la obra, diferente al clásico deus ex macchina. ${ }^{68}$

67. Dodds, 1944, p. xvii.

68. Rehm, 1992, p. 71. 
La obra está impregnada por el ritual, pero en ella es patente el tránsito hacia la tragedia. En ese tránsito desempeña un importante papel la indumentaria de Penteo disfrazado de mujer, donde los rituales tradicionales de jóvenes travestidos se con-

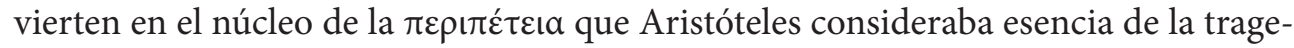
dia (Poética, 6 = 1350a 33-35). 


\section{Bibliografía}

Alcock, S.E. y Osborne, R. (1994). Placing the Gods. Sanctuaries and Sacred Space in Ancient Greece. Oxford: Clarendon Press.

Cartledge, P.A., Harvey, F.D. (eds.) (1985). Crux. Essays in Greek History presented to G.E.M de Ste. Croix. Londres: Duckworth.

Costa, V. (ed.) (2007). Filocoro di Atene. I, Testimonianze e Frammenti del'Atthis. Tivoli: TORED.

Davies, J.K. (1971). APF = Athenian Propertied Families, 600-300. Oxford: Oxford University Press.

De Schutter, X. (1987). Le culte d'Apollon Patrôos à Athènes. AC, 56, pp. 103-129.

Diller, H. (1983). Euripides' Final Phase: the Bacchae. En Segal, 1983, pp. 357-389.

Dodds, E.R. (ed.) (1944). Euripides. Bacchae. Oxford: Clarendon Press (ed. 1960).

Garland, R.S.J. (1984). Religious Authority in Archaic and Classical Athens. ABSA, 79, pp. 75-123.

Green, J.R. (1994). Theatre in Ancient Greek Society. London y New York: Routledge.

Grégoire, H. (1961). Euripide, Les Bacchantes. Paris: CUF.

Hall, E. (1989). Inventing the Barbarian. Greek Self-Definition through Tragedy. Oxford: Clarendon Press.

Hernández, L. y Alvar, J. (eds.) (2004). Actas del XXVII Congreso Internacional GIREA-ARYS IX. Jerarquías religiosas y control social en el mundo antiguo (Valladolid, 7-9 de noviembre 2002). Valladolid: Universidad de Valladolid.

Kearns, E. (1985). Change and Continuity in Religions' Structures after Cleisthenes. En Cartledge y Harvey, 1985, pp. 189-207.

Lacroix, M. (1976). Les Bacchantes d'Euripide. Introduction, texte, traduction et commentaire; analyse métrique des parties lyriques. Paris: Les Belles Lettres.

Munn, M. (2000). The School of History. Athens in the Age of Socrates. Berkeley, Los Angeles y London: University of California Press.

Osborne, R. (1994). Archaeology, the Salaminioi, and the Politics of Sacred Space in Archaic Attica. En Alcock y Osborne, 1994, pp. 143-160.

Pérez Jiménez, A. y Cruz Andreotti, G. (eds.) (1996). La religión como factor de integración y conflicto en el Mediterráneo. Madrid: Ediciones Clásicas.

Phillipart, H. (1940). Iconographie des Bacchantes d'Euripide. RBPhH, 9, pp. 5-72.

Plácido, D. (1995). La definición de los espacios sacros en la formación de la ciudad griega: el caso de Atenas. Ilu. Revista de ciencias de las religiones, 0, pp. 207-215.

Plácido, D. (1996). Las ambigüedades de la Paz. El culto de Irene en Atenas. En Pérez Jiménez y Cruz Andreotti, 1996, pp. 55-66.

Plácido, D. (2004). Las prácticas religiosas atenienses y el control social en la democracia. En Hernández y Alvar, 2004, pp. 163-167.

Rehm, R. (1992). Greek Tragic Theatre. London y New York: Routledge. 
Rodríguez Adrados, F. (1990). Eurípides, Andrómaca, Heracles loco, las Bacantes. Madrid: Alianza.

Segal, E. (ed.) (1983). Oxford Readings in Greek Tragedy. Oxford: Oxford University Press.

Thomson, G. $\left(1946^{2}\right)$. Aeschylus and Athens. A Study in the Social Origins of Drama. London: Lawrence \& Wishart.

Thomson, G. (1949). Studies in Ancient Greek Society. I. The Prehistoric Aegean. London: Lawrence \& Wishart.

Thomson, G. (1955). Studies in Ancient Greek Society. II. The First Philosophers. London: Lawrence \& Wishart.

Tovar, A. (1982). Eurípides, Tragedias, II. Las Bacantes. Hécuba. Madrid: Alma Mate.

Valdés, M., 2002 Política y Religión en Atenas Arcaica. Oxford: Archaeopress.

Valdés, M. (2015). De las Calqueas a las Hefestias: consideraciones sobre los artesanos, la ciudadanía y Hefesto. DHA, 41.2, pp. 19-40.

Wiles, D. (1997). Tragedy in Athens. Performance Space and Theatrical Meaning. Cambridge: Cambridge University Press.

Winckler, J.J. y Zeitlin, F.I. (eds.) (1990). Nothing to do with Dionysos? Athenian Drama in its Social Context. Princeton: Princeton University Press.

Wise, J. (1998). Dionysus Writes. The Invention of Theatre in Ancient Greece. Ithaca: Cornell University Press.

Zeitlin, F. (1990). Playing the Other: Theater, Theatricality, and the Feminine in Greek Drama. En Winckler y Zeitlin, 1990, pp. 63-96. 